Int. J. Electrochem. Sci., 15 (2020) $5821-5832$

\title{
Application of Glassy Carbon Electrode modified with Chitosan and ZnO nanoparticles as Enzymatic Glucose Biosensor
}

\author{
Ping Liu, Ling Yin, Xingpu $Q i^{*}$ \\ Jiangsu Agri-animal Husbandry Vocational College, 225300 China \\ *E-mail: qixingpu@ 163.com \\ doi: $10.20964 / 2020.06 .67$
}

Received: 31 January 2020 / Accepted: 4 Mart 2020 / Published: 10 May 2020

\begin{abstract}
In this study, the modified chitosan/ $\mathrm{ZnO}$ electrode was applied to electrochemical determination of glucose. $\mathrm{ZnO}$ nanoparticles ( $\mathrm{ZnO} \mathrm{NPs}$ ) was synthesized through the hydrothermal treatment and applied to modification of glassy carbon electrode (GCE). The chitosan was immobilized on ZnO NPs/GCE electrode. TEM and XRD analysis were applied to structural studies of synthesized ZnO NPs. Cyclic voltammetry and amperometry analysis were used to electrochemical sensing properties of Chit/ZnO NPs/GCE. The electrochemical studies exhibited the modified electrode had fast response, selective and stable in determining glucose. The wide linear range and detection limit of sensor were estimated 10 to $90 \mathrm{mM}$ and $0.9 \mu \mathrm{M}$, respectively. The sensor response was studied to determine glucose content in grape juice as real sample.
\end{abstract}

Keywords: Glucose; Electrochemical sensor; $\mathrm{ZnO}$ nanoparticles; Chitosan/ZnO/glassy carbon electrode

\section{FULL TEXT}

(C) 2020 The Authors. Published by ESG (www.electrochemsci.org). This article is an open access article distributed under the terms and conditions of the Creative Commons Attribution license (http://creativecommons.org/licenses/by/4.0/). 